\title{
DESAFIOS DO CONSÓRCIO INTERMUNICIPAL DO ABC - DE ARTICULADOR PARA EXECUTOR DE POLITICAS PUBLICAS DE INTERESSE COMUM?
}

\author{
CHALLENGES FACING THE INTER-MUNICIPAL CONSORTIUM OF THE \\ ABC REGION: FROM ARTICULATOR TO EXECUTOR OF PUBLIC \\ POLICIES WITH A COMMON INTEREST?
}

\begin{abstract}
Kelly Roberta Ferracini ${ }^{1}$
\section{RESUMO}

Este artigo trata do atual momento do Consórcio Intermunicipal Grande $\mathrm{ABC}$, considerando a retomada da agenda regional-metropolitana a partir da década de 2000. Consolidado como referência nacional em articulação regional de municípios e cooperação federativa, o consórcio proporcionou a integração entre as sete cidades, assumindo papel de destaque no debate que conduziu à formalização da Região Metropolitana de São Paulo (RMSP), e também no lançamento de novas iniciativas compartilhadas em âmbito regional. Em 2011, houve muitas atividades promovidas pelos grupos de trabalho GT, desde desenvolvimento econômico e a prioridade à criança, até meio ambiente, mobilidade e segurança pública. O consórcio deu ainda passos importantes para o aperfeiçoamento da estrutura interna e construção institucional, visando à adequada execução do planejamento estratégico 2010-2011. Agora em 2013, com a transição de governo e reestruturação dos GTs, que serão indicados pelos gestores e o novo presidente, o Consórcio enfrenta o desafio de dar continuidade às ações do Planejamento Estratégico Regional 2011-2020 e executar convênios e acordos estabelecidos em 2011 e 2012.
\end{abstract}

Palavras-chave: Consórcio Intermunicipal do Grande ABC; Planejamento Estratégico; Política Pública e Governança.

\begin{abstract}
This article focuses on the current status of the Inter-municipal Consortium of the ABC Region, considering the resumption of the metropolitan and regional agenda beginning in the 2000s. Having been consolidated as a nationwide benchmark in the regional articulation of districts and towns and federal cooperation, the consortium enabled the integration of seven towns, taking on the main role in the debate that led to the formalization of the Metropolitan Region of São Paulo (RMSP), and also the launch of new shared initiatives in the region. In 2011, many activities were promoted by the work groups, ranging from economic development and priority for children to the environment, mobility and public safety. The consortium also took important steps towards improving internal structure and institutional construction, with a view to putting the strategic plan for 2010-2011 into action. Now, in 2013, with the transition of the government and the restructuring of the work groups, which will be conducted by the managers and the new president, the consortium faces the challenge of carrying on the regional strategic plan for 2011-2020 and fulfilling agreements made in 2011 and 2012.
\end{abstract}

Key words: Inter-municipal Consortium of the ABC Region; Strategic Planning; Public Policy and Governance.

Recebido 10/05/2013; Aceito 27/06/2013

\footnotetext{
${ }^{1}$ Mestranda do Programa de Pós-Graduação em Planejamento e Gestão do Território, Universidade Federal do $A B C$.
} 


\section{Introdução}

Segundo Denaldi, Klink e Souza (2010), não há modelo único de governança regionalmetropolitana. Governar é um processo interativo, já que nenhum agente detém sozinho o conhecimento e os recursos necessários para resolver problemas de forma unilateral. A ausência da governança colaborativa regional dificulta a operacionalização de políticas públicas de interesse comum no território, dentre as quais pode ser destacada a política habitacional. De acordo com o Plano Municipal de Habitação do Município de Diadema (2008), o município terá que atender a um déficit habitacional, projetado até 2020, de 18.368. Tanto o poder público quanto a iniciativa privada não dispõem de terras vazias que estejam em condições de atender a essa demanda. O município conta com apenas 30\% de terras disponíveis em relação ao déficit habitacional. Deste modo, para resolver o problema habitacional do município de Diadema, é necessário haver atendimentos habitacionais em outros municípios da Região Metropolitana de São Paulo. Investir esforços na agenda regional para discussão e difusão de políticas públicas territoriais estratégicas é a forma de, em longo prazo, conter e sanar o déficit habitacional.

Para responder a essas questões de interesse comum, tem-se presenciado o ressurgimento de ações no planejamento governamental para o enfrentamento dos problemas e desequilíbrios econômicos, sociais e produtivos a partir de uma agenda regional. Nos diferentes níveis de governo observam-se iniciativas, tais como a experiência recente no Governo Federal da Política Nacional de Desenvolvimento Regional (PNDR).

A Emenda Constitucional de 1998 acrescentou à redação do artigo 241 da Constituição Federal de 1988 a figura dos consórcios públicos, na qual estabelece que a União, os Estados, o Distrito Federal e os Municípios disciplinarão, por meio de lei, os consórcios públicos, e os convênios de cooperação entre os entes federados estão autorizados a fazer a gestão associada de serviços públicos, bem como a transferência total ou parcial de encargos, serviços, pessoal e bens essenciais à continuidade dos serviços transferidos.

A Lei Federal $n^{\circ}$ 11.107, de 6 de abril de 2005, Lei dos Consórcios Públicos, regulariza a gestão associada e a cooperação no Brasil para auxiliar no enfrentamento dos problemas ocasionados pelo aumento dos municípios e formação das áreas metropolitanas. Os problemas a cargo do governo municipal muitas vezes exigem soluções que extrapolam o alcance da capacidade de ação da prefeitura em termos de investimentos, recursos humanos e financeiros para custeio e atuação política. Além disso, grande parte dessas soluções exige ações conjuntas, pois diz respeito a problemas que afetam, simultaneamente, mais de um município. As parcerias provenientes dos consórcios públicos entre as prefeituras aumentam a capacidade de um grupo de municípios solucionar problemas comuns sem lhes retirar a autonomia.

A expectativa é de que a regulamentação dos consórcios públicos possibilite a constituição de instrumentos de cooperação federativa, adequados a diferentes escalas territoriais e a múltiplos objetivos, assim como seja superada a insegurança jurídica dos arranjos de cooperação entre os entes públicos.

O governo estadual e federal, tradicionais canais de solicitação de recursos utilizados pelos municípios, apresentam, em geral, baixa capacidade de intervenção. E deixar que o governo estadual ou federal assuma ou realize atividades de âmbito local ou regional, que poderiam ser realizados pelos municípios, pode significar uma renúncia à autonomia 
municipal, retirando dos cidadãos a possibilidade de intervir diretamente nas ações públicas que lhes dizem respeito.

O caso mais paradigmático de consorciamento no Brasil é o do Consórcio Intermunicipal do Grande ABC, cuja inspiração intelectual e política vieram do então prefeito de Santo André, Celso Daniel.

Em dezembro de 1990, os sete prefeitos da região criaram uma associação: o Consórcio Intermunicipal das Bacias Billings e Tamanduatehy, que surgiu sob um modelo voltado à gestão de recursos hídricos, tendo como um de seus objetivos específicos a preocupação com a destinação dos resíduos sólidos da região, e outro, mais genérico, voltado à questão do desenvolvimento urbano e econômico, que se constituiu para pensar e resolver os problemas comuns das cidades da região que sofriam com os impactos da crise econômica da década de 1990 e os efeitos da reestruturação e flexibilização dos processos produtivos com a globalização.

Mesmo reconhecendo que ainda se está muito distante da consolidação efetiva da cooperação federativa na operacionalização da política pública de interesse comum no território, não se pode desconsiderar que, nos últimos anos, uma série de iniciativas tomadas deu um novo arranjo político-institucional na definição de diretrizes e políticas do desenvolvimento urbano e regional na região do Grande $\mathrm{ABC}$.

Em 2011, uns dos grandes destaques sobre a atuação do consórcio foi a interação com os governos estadual e federal, com a entrega de pautas baseadas no planejamento estratégico feitos pelos GTs, onde foram solicitadas intervenções compartilhadas para áreas fundamentais, como saúde, educação, mobilidade urbana, segurança pública, desenvolvimento econômico e infraestrutura urbana. Em 2012, essa agenda institucional e de trabalho precisa ter continuidade para conseguirmos ainda mais conquistas para nossa região (Mario Reali, Prefeito de Diadema). (CONSÓRCIO INTERMUNICIPAL GRANDE ABC, 2011, p. 11).

A partir desses relatos, pretendeu-se levantar a discussão para além do formalismo e das intenções sobre o atual momento do Consórcio Intermunicipal Grande $A B C$, o novo ambiente macroinstitucional favorável, mas que não apresenta tantos avanços no processo de articulação regional, havendo a possibilidade de o Consórcio executar políticas públicas de interesse comum no território. Será analisado na primeira sessão o surgimento e trajetória do Consórcio Intermunicipal atrelado ao momento histórico de reestruturação produtiva que se encontrava nas décadas de 1990 a 2000. Na segunda sessão, será abordado o momento recente pós-2000: Planejamento Estratégico no Brasil e no Grande ABC e os avanços Macroinstitucionais, trazendo a discussão referente à transição de organismo articulador para uma instituição executora de políticas públicas. Na terceira sessão. Será apresentada uma análise exploratória dos desafios de Implementação e Operacionalização do Planejamento Estratégico do Consórcio Intermunicipal do Grande ABC, com base no relatório 2011 de prestação de contas, relatórios de atividades, acordos e agendas entre os municípios. Pretendese ampliar a discussão para além do formalismo e das intenções no sentido de considerar a vontade política na cooperação federativa, apresentando uma abordagem empírica baseada em pesquisa documental das ações executadas em 2011 e uma análise dos planos de governo dos 
prefeitos eleitos em 2013, com a abordagem e comprometimento dos novos prefeitos nos seus governos com o Consórcio.

\section{Breve Trajetória do Consórcio Intermunicipal do Grande ABC - 1990 a 2000}

A cooperação entre os municípios é conhecida como consórcio intermunicipal, destinado a solucionar problemas e obter resultados conjuntos de natureza superior às capacidades política, financeira e operacional individual de seus integrantes. No Estado de São Paulo, os consórcios intermunicipais estavam previstos desde a Constituição Estadual de 1891.

A partir de meados de 1980, o país passou a sofrer crônica e elevada inflação, alternada por períodos de controle de preços, o que desestruturava a capacidade de planejamento governamental em diversos níveis. Os municípios, por sua vez, sentiam o aumento das demandas sociais diretamente, seja porque o desemprego reduzia a renda disponível das famílias, seja porque, a partir da Constituição Federal de 1988, ampliou-se a gestão de políticas sociais como saúde, educação e assistência social, as quais, porém, continuavam dependentes de fontes de receitas que estavam além de sua governabilidade. A União, os Estados, o Distrito Federal e os Municípios disciplinarão, por meio de lei, os consórcios públicos e os convênios de cooperação entre os entes federados, autorizando a gestão associada de serviços públicos, bem como a transferência total ou parcial de encargos, serviços pessoais e bens essenciais à continuidade dos serviços transferidos.

Nesse contexto, os municípios ampliam as atividades de promoção do desenvolvimento local, aproveitando suas potencialidades. $\mathrm{O}$ desenvolvimento inclui aspectos amplos, como a dinamização de capacidades que possibilitem escolhas substantivas por parte da população, não apenas daqueles ligados ao mercado de trabalho e bens, mas também aos grupos com maior vulnerabilidade social.

Apesar da fragilidade macroinstitucional que ainda caracteriza o cenário brasileiro, verificou-se uma série de iniciativas recentes no âmbito do processo de repactuação da federação brasileira (KLINK, 2010). No Estado de São Paulo, a utilização dos Consórcios Intermunicipais está inserida nessa perspectiva de desenvolvimento mais abrangente do que meramente de suporte à produção material, com forte apelo à participação e democratização das políticas públicas.

Segundo Denaldi, Klink e Souza (2010), o arranjo que norteia a gestão e financiamento das áreas metropolitanas é frágil. Não há um modelo único de governança metropolitana. Os consórcios públicos (arranjo mais novo na estrutura de governança metropolitana) e os arranjos estadualizados das regiões metropolitanas representam dois exemplos de um conjunto mais amplo de experiências interfederativas.

Na região do Grande $\mathrm{ABC}$, um dos polos industriais mais importantes do Brasil e da América Latina (com presença da cadeia produtiva de automóveis e do segmento petroquímico), a expansão desordenada transbordou os limites da capital paulista, chegando a municípios vizinhos, como Guarulhos, São Bernardo do Campo e a faixa São Caetano do Sul e Santo André. Consequentemente, o crescimento populacional da Região do Grande ABC desde a década de 1960 foi expressivo, como apresentado na Tabela 1 
TABELA 1 - Crescimento populacional da Região do Grande ABC

\begin{tabular}{|l|r|r|r|r|r|r|}
\hline Município/Região & \multicolumn{1}{c|}{$\mathbf{1 9 6 0}$} & \multicolumn{1}{c|}{$\mathbf{1 9 7 0}$} & \multicolumn{1}{c|}{$\mathbf{1 9 8 0}$} & \multicolumn{1}{c|}{$\mathbf{1 9 9 1}$} & \multicolumn{1}{c|}{$\mathbf{2 0 0 0}$} & \multicolumn{1}{c|}{$\mathbf{2 0 1 0}$} \\
\hline Santo André & 245.147 & 418.826 & 553.072 & 616.991 & 649.331 & 673.914 \\
\hline $\begin{array}{l}\text { São Bernardo do } \\
\text { Campo }\end{array}$ & 82.411 & 201.662 & 425.602 & 566.893 & 703.177 & 765.203 \\
\hline São Caetano do Sul & 114.421 & 150.130 & 163.082 & 149.519 & 140.159 & 149.571 \\
\hline Mauá & 28.924 & 101.700 & 205.740 & 294.998 & 363.392 & 417.281 \\
\hline Diadema & 12.308 & 78.914 & 228.660 & 305.287 & 357.064 & 386.039 \\
\hline Rio Grande da Serra & 3.955 & 8.397 & 20.093 & 29.901 & 37.091 & 44.084 \\
\hline Ribeirão Pires & 17.250 & 29.048 & 56.532 & 85.085 & 104.508 & 113.043 \\
\hline Grande ABC & 504.416 & 988.677 & 1.652 .781 & 2.048 .674 & 2.354 .722 & 2.549 .135 \\
\hline
\end{tabular}

Fonte: IBGE (2010).

Essa expansão desencadeia problemas relacionados à habitação, infraestrutura e mobilidade urbana, que ultrapassam a jurisdição de um único município. Observa-se que, nos anos 1990, houve um movimento do Grande ABC no sentido de criar governanças regionais para resolver problemas comuns no território. Nesse sentido, é possível afirmar que a primeira conquista alcançada, ainda na década de 1990, foi a concretização de um modelo de gestão que possibilitou a priorização das demandas dos sete municípios da região do $\mathrm{ABCD}$, o Consórcio Intermunicipal Grande $\mathrm{ABC}$, que representa articulação intermunicipal entre os sete prefeitos das cidades com o objetivo de viabilizar mecanismos de coordenação intermunicipal suprapartidária.

Durante o período de 1993 a 1996, por falta de priorização da questão regional pelos prefeitos em exercício, o Consórcio Intermunicipal perde força na articulação regional. Ao mesmo tempo, entretanto, algumas iniciativas relevantes serão tomadas pela própria sociedade civil organizada, refletindo a maturidade da identidade regional e a preocupação com problemas específicos da região. O Fórum da Cidadania do Grande ABC representa, nesse sentido, uma das iniciativas mais importantes. É composto de um grande número de instituições da sociedade civil, como associações de empresas, sindicatos de trabalhadores, movimentos ecológicos e grupos ambientais, entre outros. O fórum surge, na realidade, de uma discussão inicial sobre as distorções na representatividade político-institucional da região, que culmina com a campanha Vote no Grande ABC, em março de 1994. Em julho de 1994, no lançamento do Manifesto do Grande $\mathrm{ABC}$, o fórum começa a se manifestar como nova instância de representatividade da região.

Em 1997, a eleição dos sete prefeitos no mês de janeiro foi um passo decisivo na retomada da agenda regional dos governos locais. Foi elaborado, consensualmente, o estatuto da chamada "Câmara da Região do Grande ABC", criada e aprovada oficialmente em 12 de março de 1997, na presença das lideranças regionais mais importantes e do governo estadual. Arena privilegiada para planejamento estratégico regional, inclusive para aspectos relevantes do desenvolvimento urbano. Em 1998, surge a agência de desenvolvimento econômico do grande $\mathrm{ABC}$, cuja principal missão era a revitalização econômica da região pela articulação de atividades voltadas ao fomento dos micro e pequenos empresários, sistemas de informações (para os setores privado e público) e o marketing regional. Isso trouxe de 
imediato uma ampla mobilização social que, em médio prazo, resultou em importantes realizações que emergiram no âmbito do Planejamento Estratégico da Câmara Regional, como o plano de macrodrenagem e a construção dos diversos piscinões; a implantação dos Hospitais Regionais do Serraria, em Diadema, e Mário Covas, em Santo André; do tramo sul do Rodoanel metropolitano; a ampliação da produção do Polo Petroquímico e a implantação da UFABC e da UNIFESP na região. Os avanços do trabalho conjunto das sete cidades por meio do Consórcio podem ser representados pela estruturação da Casa Abrigo Regionais, que atende mulheres vítimas de violência (CONSÓRCIO INTERMUNICIPAL DO GRANDE $\mathrm{ABC}, 2011)$.

Em 2000, foi previsto no Plano Estratégico que os municípios membros elaborassem conjuntamente estratégias, ações e programas com vistas à melhoria urbana com inclusão social.

Segundo Denaldi, Klink e Souza (2010), a partir de 2003, o governo nacional, por meio de uma articulação entre o Ministério das Cidades, o Ministério de Integração Nacional e a Subchefia de Assuntos Federativos da Casa Civil da Presidência da República, reinseriu o tema da gestão metropolitana na pauta da agenda política do país.

Em 2010, do Consórcio em órgão multissetorial de direito público e natureza autárquica, em atendimento à Lei Federal $n^{\circ} 11.107 / 05$, a nova configuração possibilita à instituição abrir processos de licitação para atender aos interesses dos sete municípios, firmar acordos entre as prefeituras e receber recursos do Estado e da União, além dos organismos internacionais. O Consórcio do Grande ABC Paulista está dividido por eixos de atuação, infraestrutura, Desenvolvimento Econômico e Regional, Desenvolvimento Urbano e Gestão Ambiental, Saúde, Educação, Cultura e Esporte, Assistência, Inclusão Social e Direitos Humanos, e Segurança Pública.

\section{Planejamento estratégico no Grande $\mathrm{ABC}$ e avanços macroinstitucionais}

No ABC, a câmara regional se coloca como arena privilegiada para o Planejamento Estratégico regional, inclusive para aspectos relevantes do Desenvolvimento Urbano. Em 2000, era previsto no Plano Estratégico que os municípios membros elaborassem conjuntamente estratégias, ações e programas com vistas à melhoria urbana com inclusão social. Durante os dez anos de Planejamento Regional Estratégico, de 2000 a 2010, pode-se citar como exemplo de cooperação bem-sucedida o caso da Favela Naval, localizada nas divisas entre os municípios de São Bernardo do Campo e Diadema.

Trata-se de uma intervenção integrada que exigia a colaboração bilateral entre as referidas prefeituras para viabilizar a abertura do viário regional e promover a urbanização e recuperação da Favela Naval. A ausência da governança colaborativa dificultou e paralisou a execução do projeto. Retomada em 2009, com recursos oriundos do Programa de Aceleração do Crescimento (PAC), durante as novas administrações municipais, foi estabelecido um canal de diálogo para que as intervenções viárias e habitacionais acontecessem. Dessa forma, as intervenções ocorrem integradas espacialmente e no cronograma de obras (DENALDI; KLINK; SOUZA, 2010).

Desse modo, formas de governança metropolitana poderão ajudar no fortalecimento das capacidades institucionais dos municípios, desde que sejam definidos critérios claros na partilha dos recursos e responsabilidades. Os governos municipais podem ampliar o atendimento aos cidadãos e o alcance das políticas públicas por conta da disponibilidade 
maior de recursos, do apoio dos demais municípios e compartilhamento de recursos. A relação de transparência durante as decisões públicas abre espaço para apropriação dos espaços de participação popular. A articulação de um consórcio intermunicipal pode criar melhores condições de negociação dos municípios com os governos estaduais e federais, ou com as a entidades da sociedade, empresas ou agências estatais.

Atualmente, os investimentos realizados com o PAC pelo governo federal representam uma grande oportunidade para os municípios atenderem seus déficits habitacionais qualitativos.

Klink, Denaldi e Souza (2010) reafirmam essa necessidade premente de articulação e de uma governança regional para enfrentar o desafio da política habitacional de interesse social. Portanto, do ponto de vista da ação dos governos municipais envolvidos, estabelecer como princípios o fortalecimento dos consórcios intermunicipais pode produzir resultados positivos na operacionalização das políticas públicas de interesse comum no território.

Assim, os consórcios intermunicipais podem criar condições para que seja possível atingir resultados que não seria possível a nenhuma prefeitura isoladamente, ou mesmo a soma dos esforços individuais de cada uma delas, a operacionalização de políticas públicas de interesse comum no território, que garanta acesso aos direitos sociais no âmbito abrangente e ultrapasse o limite dos municípios, resultando em qualidade de vida na metrópole.

Nesse sentido, Abrucio, Sano e Sydow (2010) indicam que o comportamento cooperativo só se dará de forma isolada ou simultaneamente quando ocorrerem três coisas: 1) existência de forte identidade regional, alicerçadas por instituições duradouras; 2) articulação indutiva do governo estadual e federal oferecendo incentivos para colaboração ou condicionando o repasse de recursos a existência de parcerias; 3) necessidade de se estabelecer fóruns ou árbitros federativos que tomem decisões em favor da cooperação. A região do Grande $\mathrm{ABC}$ já possui duas das três condições assinaladas, ficando a cargo dos outros níveis de governo oferecer uma coordenação eficiente e os incentivos para colaboração.

\section{Momento recente pós-2000: mudanças socioinstitucionais no Consórcio - De articulação para operacionalização de políticas públicas territoriais?}

Entre 2009 e 2012, foram realizados esforços no sentido de buscar uma concertação entre os poderes públicos, nas esferas municipais, estadual e federal, retomando também os canais de diálogo com a sociedade civil.

Essa estruturação trouxe importantes conquistas, como a viabilização de recursos para as áreas de defesa civil e combate às enchentes, proteção às mulheres vítimas de violência, saúde regional, segurança pública, defesa do consumidor, mobilidade urbana através da extensão da linha bronze para o ABC por meio da implantação de um sistema de monotrilho.

Ao mesmo tempo, colocou o Consórcio Intermunicipal Grande $\mathrm{ABC}$ como interlocutor reconhecido também no novo arranjo de governança metropolitana estabelecido no Conselho de Desenvolvimento da Região Metropolitana de São Paulo, dialogando em nome das sete prefeituras que compõem a sub-região do ABCD. 
O Consórcio Intermunicipal Grande $\mathrm{ABC}$ segue sendo um instrumento fundamental para o desenvolvimento da região. Atuamos em parceria com os prefeitos das outras seis cidades em áreas que vão de segurança como comunicação integrada e desarmamento à mobilidade urbana, articulando, por exemplo, o novo Metro leve. Também atuamos junto ao Governo do estado, exigindo mais investimentos para o Grande ABC (Luiz Marinho Prefeito de São Bernardo do Campo). (CONSÓRCIO INTERMUNICIPAL GRANDE ABC, 2011, p. 11).

Porém, políticas públicas envolvendo temas estruturantes, como a mobilidade metropolitana, infraestrutura urbana e habitação, que demandam expressivo aporte de recursos e amplo entendimento entre os entes federados, não foram ainda plenamente concretizadas pelo caráter inédito de institucionalidade dos consórcios públicos, ou pela falta de consenso e divergência de interesses entre as partes envolvidas.

Os avanços da integração na Grande São Paulo demandam também a definição em torno do papel protagonista da capital paulista como centro catalisador das grandes questões metropolitanas, articulando-se de modo inovador e propositivo com os 38 municípios que integram uma das maiores metrópoles globais de nosso tempo.

Também de suma importância é a adesão efetiva e prática do governo estadual, por meio da Secretaria de Desenvolvimento Metropolitano, que ainda atua como mediadora entre órgãos estaduais e as demandas municipais, muitas vezes sujeitas a situações políticas locais.

Ou seja, o comprometimento com a implementação das políticas públicas e aplicação dos recursos em escala regional e metropolitana necessitam de entendimentos entre o governo estadual, a capital e os 38 municípios por meio de um planejamento de ações que vise a um pacto entre os entes.

Esses acordos podem ser definidos como a busca de consensos para a execução das políticas públicas. Porém, para que isso ocorra, será fundamental que cada uma das partes envolvidas abra mão de certa parcela de poder inerente às suas funções específicas. Outra ação necessária é a consolidação de um corpo técnico efetivo e permanente para a gestão metropolitana que sobreponha os mandatos eletivos e mantenha em curso o que foi acordado.

As cidades que fazem parte dos grandes aglomerados urbanos não podem mais prescindir de ações integradas que vão muito além dos limites locais. As políticas públicas de alcance metropolitano não serão viáveis ou passíveis de serem implantadas se não contarem uma ação que vislumbre o conjunto dos municípios que integram a Grande São Paulo com base na gestão pública integrada e no diálogo permanente com a sociedade civil.

A participação social é um desafio que ainda não foi enfrentado, mesmo nas experiências mais inovadoras, como a do Consórcio Intermunicipal Grande ABC, que ao longo de sua trajetória não consolidou de maneira permanente o papel da sociedade civil. Essa situação poderá levar à perda de credibilidade e de adesão da opinião pública aos programas implantados pelos órgãos de caráter público. 


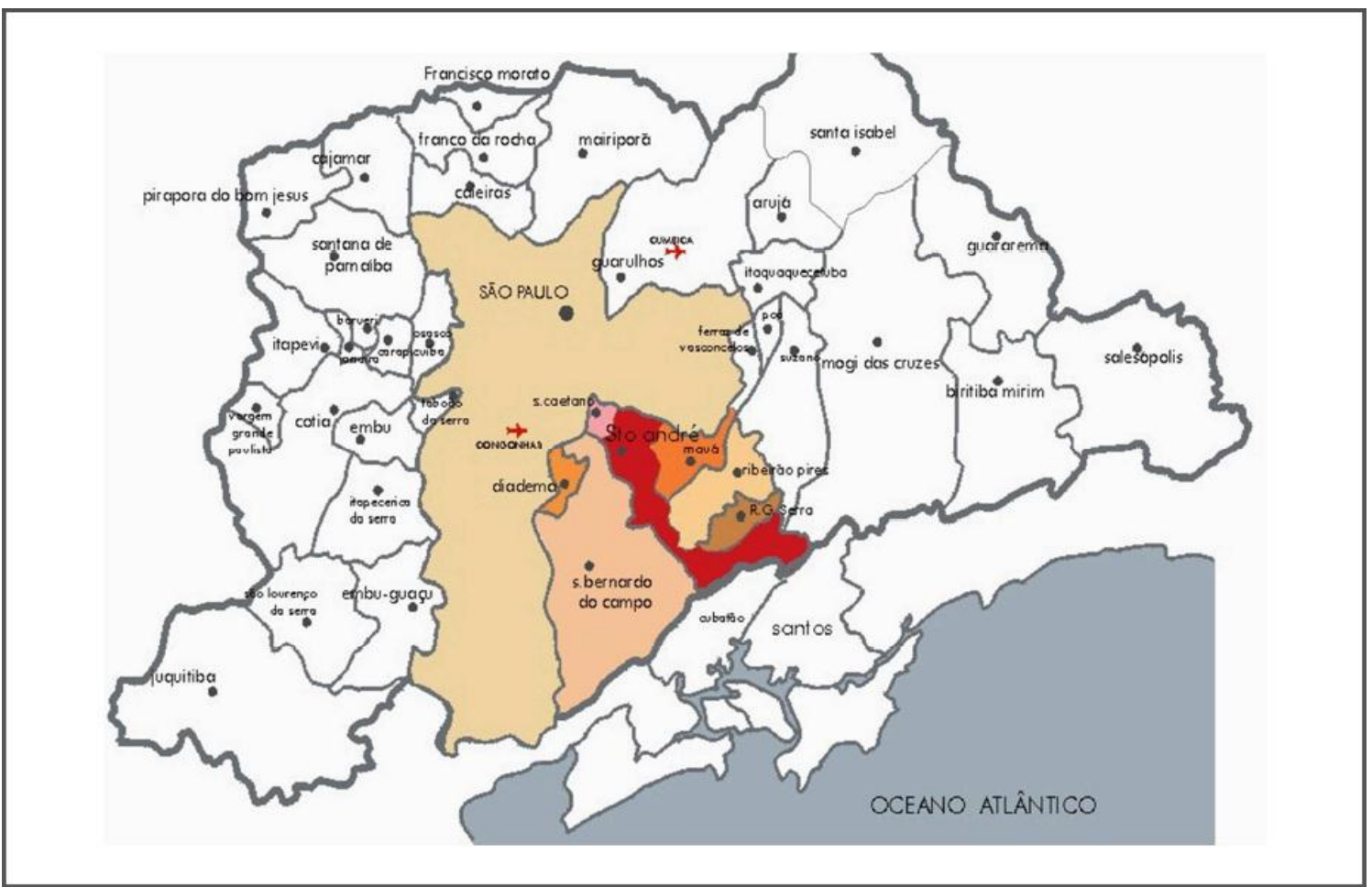

FIGURA 1 - Análise exploratória dos desafios de Implementação e Operacionalização do Planejamento Estratégico do Consórcio Intermunicipal do Grande ABC Fonte: Acervo Consórcio Intermunicipal Grande ABC.

Nos últimos vinte anos, e graças ao espírito visionário de Celso Daniel, o Consórcio Intermunicipal Grande $\mathrm{ABC}$ acumulou uma trajetória de referência em política regional. Neste último período, pós-2000, marcado pela transição para uma entidade de direito público, criou-se um novo patamar de desafios e uma nova perspectiva de enfrentamento dos problemas regionais e das questões metropolitanas. Umas das iniciativas mais relevantes, o Programa Casa Abrigo Regional, reconhecida por seus méritos no combate à violência contra a mulher, recebeu do governo estadual o Prêmio Chopin Tavares de Lima.

Klink (2011) classifica o Grande ABC como uma cidade-região que enfrenta o atual desafio de criar novas formas de participação e democracia local, incorporando diversos atores e criando, desse modo, sistemas locais baseados em relações mais cooperativas. Assim se abre uma nova perspectiva de atuação do Consórcio e também se colocam desafios importantes para as sete prefeituras do $\mathrm{ABCD}$, nos próximos dez anos de implementação. $\mathrm{O}$ Planejamento Regional Estratégico do Consórcio Intermunicipal Grande ABC 2011-2020 é o resultado da experiência elaborada coletivamente pelos integrantes dos 25 Grupos de Trabalho, tendo como eixos estruturantes a Infraestrutura; Segurança Pública; Saúde; Assistência; Inclusão Social; Direitos Humanos; Educação, Cultura e Esporte; Desenvolvimento Econômico Regional; Desenvolvimento Urbano; e a Gestão Ambiental e Institucional. De agosto até o fim de setembro, participaram os 25 GTS de oficinas de trabalho, com o objetivo de planejar as ações que entenderam imprescindíveis para a região nos próximos dez anos, dentro de cada assunto, no âmbito regional.

A operacionalização do Planejamento Regional Estratégico 2010-2011 inicia em março de 2011. As sete prefeituras definiram as reivindicações prioritárias a serem negociadas com os governos estadual e federal, as propostas foram posteriormente apresentadas aos 
presidentes das sete câmaras municipais e as bancadas do Grande ABC na Assembleia Legislativa e Câmara Federal.

Foram definidas agendas de prioridade, que resultou em dois desdobramentos políticos de relevância: a entrega da carta do $\mathrm{ABC}$ e a apresentação da Agenda Metropolitana no mês de maio ao atual presidente do Consórcio em exercício, Mario Reali. Os pontos considerados estratégicos pela assembleia de Prefeitos para a região do Grande $\mathrm{ABC}$ foram: mobilidade, saúde, segurança, inovação tecnológica e desenvolvimento econômico. A atual ministra do planejamento, orçamento e gestão, Miriam Belchior, recebeu o documento com as prioridades da região no relacionamento com o governo federal.

Em 2011 houve iniciativas em várias áreas dos GTs, com destaque para os GTs de infraestrutura; desenvolvimento econômico e regional; desenvolvimento urbano e gestão ambiental; estabelecimento de acordos e convênios com o Ministério da Justiça para a divulgação de dados regionais da pesquisa de Emprego e Desemprego no Ministério da Ciência e Tecnologia; monitoramento de Desastres Naturais e criação do Programa Regional de Redução de Riscos; Programa de comunicação integrada das Guardas Civis Municipais; e a captação de 800 mil para a elaboração do Plano Regional de Mobilidade.

Quanto aos investimentos realizados, tem relevância o volume de recursos destinados pelo Consórcio à estruturação dos sete municípios na Defesa Civil. Foram adquiridos 14 veículos e materiais de apoio de atuação preventiva e emergencial do GT Defesa Civil na região. O Programa Casa Abrigo continua sendo o principal destinatário de recursos orçamentários do Consórcio, com investimentos em manutenção de equipamentos de segurança e aquisição de um novo veículo.

Contudo, observou-se que 2011 foi um ano de iniciativas e convênios importantes, reestruturação interna e retorno da sociedade civil, em dezembro de 2011, com a constituição do Conselho Consultivo, que reúne representantes da sociedade civil organizada para atuar como órgão consultivo da Assembleia Geral dos prefeitos, propor planos e programas de acordo com as finalidades do Consórcio. O ano de 2013 será o momento de colocar em execução os acordos e as iniciativas de cooperação federativa.

Entretanto, conforme análise prévia nos planos de governos dos prefeitos eleitos, que assumiram as prefeituras dos sete municípios do grande ABC em 2013, fica evidente que há um distanciamento entre o discurso de cooperação e a real vontade política. A seguir, a relação dos candidatos eleitos e suas intenções para com o consórcio durante sua gestão (Quadro 1). 
QUADRO 1 - Candidatos eleitos x intenções

\begin{tabular}{|c|c|c|c|c|c|}
\hline Cidade & \begin{tabular}{|l|} 
Candidat \\
os a \\
prefeito
\end{tabular} & $\begin{array}{l}\text { Partid } \\
\text { o }\end{array}$ & \begin{tabular}{|l|} 
Plano \\
de \\
governo
\end{tabular} & $\begin{array}{l}\text { Menciona } \\
\text { o } \\
\text { Consórcio }\end{array}$ & $\begin{array}{l}\text { Propostas sincronizadas } \\
\text { com as políticas do } \\
\text { Consórcio }\end{array}$ \\
\hline Diadema & \begin{tabular}{|l} 
Lauro \\
Michels
\end{tabular} & PV & Sim & Sim & $\begin{array}{l}\text { Não faz menção ao } \\
\text { Consórcio. }\end{array}$ \\
\hline $\begin{array}{l}\text { São } \\
\text { Bernardo } \\
\text { do Campo }\end{array}$ & $\begin{array}{l}\text { Luiz } \\
\text { Marinho }\end{array}$ & PT & Sim & Sim & $\begin{array}{l}\text { Continuidade da cidade de } \\
\text { São Bernardo do Campo } \\
\text { dentro do espaço do } \\
\text { consórcio. }\end{array}$ \\
\hline $\begin{array}{l}\text { Santo } \\
\text { André }\end{array}$ & $\begin{array}{l}\text { Carlos } \\
\text { Grana }\end{array}$ & PT & Sim & Sim & $\begin{array}{l}\text { Fortalecimento do Consórcio } \\
\text { e os eixos de atuação. }\end{array}$ \\
\hline $\begin{array}{l}\text { São } \\
\text { Caetano }\end{array}$ & \begin{tabular}{|l} 
Paulo \\
Pinheiro
\end{tabular} & $\begin{array}{c}\text { PMD } \\
\text { B }\end{array}$ & Sim & Não & $\begin{array}{l}\text { Não faz menção ao } \\
\text { Consórcio. }\end{array}$ \\
\hline $\begin{array}{l}\text { Ribeirão } \\
\text { Pires }\end{array}$ & \begin{tabular}{|l} 
Saulo \\
Benevide \\
s
\end{tabular} & $\begin{array}{l}\text { PMD } \\
\text { B }\end{array}$ & Sim & Não & $\begin{array}{l}\text { Não faz menção ao } \\
\text { Consórcio. }\end{array}$ \\
\hline $\begin{array}{l}\text { Rio Grande } \\
\text { da Serra }\end{array}$ & $\begin{array}{l}\text { Gabriel } \\
\text { Maranhão }\end{array}$ & PSDB & Sim & Não & $\begin{array}{l}\text { Não faz menção ao } \\
\text { Consórcio. }\end{array}$ \\
\hline Mauá & $\begin{array}{l}\text { Donizete } \\
\text { Braga }\end{array}$ & PT & Sim & Sim & $\begin{array}{l}\text { Fortalecer a participação de } \\
\text { Mauá no Consórcio } \\
\text { Intermunicipal. }\end{array}$ \\
\hline
\end{tabular}

Todos os candidatos eleitos que assumiram as prefeituras em 2013 abordaram a questão da infraestrutura, mobilidade urbana e desenvolvimento urbano como questões cruciais no $\mathrm{ABC}$ durante a campanha eleitoral, alguns sem mencionar o Consórcio Intermunicipal, outros reforçando que as questões de infraestrutura, mobilidade urbana e desenvolvimento urbano requerem soluções intersetoriais e intragovernamentais, sendo imprescindível construir uma agenda regional eficaz. $\mathrm{Na}$ atualidade, o Consórcio Intermunicipal Grande $\mathrm{ABC}$ se depara com um ambiente macroinstitucional favorável, mas não apresenta tantos avanços no processo de articulação regional.

\section{Considerações finais}

Mesmo que de forma preliminar, esta análise mostra que o consórcio se encontra em um ponto de inflexão em sua trajetória de desenvolvimento, no sentido de se preparar para transformar-se de um organismo de planejamento para uma instituição também responsável pela execução de serviços de interesse comum. Da mesma forma, o Planejamento Regional Estratégico, envolvendo sete municípios com a missão de trabalhar todas as políticas públicas do território, ainda requer um tempo de maturação até colher seus frutos.

Entretanto, pretende-se aqui iniciar o debate sobre a relação entre o discurso e as instancias regionais, de um lado, e o real comprometimento político com as instituições, de outro, o olhar que cada município traz para a instituição e sua capacidade de solucionar 
problemas em comum no território. Segundo Bresciani (2012), a necessária busca por qualidade de vida no território regional, por um novo modelo de desenvolvimento econômico regional, por um planejamento urbano articulado, por uma gestão ambiental mais incisiva e por uma política social integrada colocam aos prefeitos, secretários e representantes dos governos municipais nos grupos de trabalho do Consórcio, e essa é uma missão crítica para a qual a contribuição do Consórcio poderá alcançar uma nova escala, de alta relevância política.

Por fim, é necessário aprofundar as pesquisas documentais, atas, acordos, agendas dos municípios para o consórcio, com mais empenho nos desafios, limites e perspectivas do Consórcio Intermunicipal Grande $\mathrm{ABC}$, analisando a complexidade da escala regional (autonomia municipal) correlacionada às escalas estadual e federal, como provedor e articulador dos investimentos das políticas públicas de interesse em comum no território.

\section{REFERÊNCIAS}

ABRUCIO, Fernando Luiz; SANO, Hironobu; SYDOW, Cristina Toth. Radiografia do associativismo territorial brasileiro: tendências, desafios e impactos sobre as regiões metropolitanas. In: KLINK, Jeroen Johannes (Org.). Governanças das metrópoles: conceitos, experiências, perspectivas. São Paulo: Annablume, 2010. p. 21-48.

BRESCIANI, Luis Paulo. Tradição e transição: o caso do Consórcio Intermunicipal Grande ABC. Cadernos Adenauer XII (2011), n. 4, Rio de Janeiro: Fundação Konrad Adenauer, abril 2012.

CONSÓRCIO INTERMUNICIPAL GRANDE ABC. Relatório de Gestão 2011. Disponível em: <http://www.consorcioabc.sp.gov.br/documentos/relatorio-de-gestao-2011>. Acesso em: 28 jul. 2013.

DENALDI, Rosana; KLINK, Jeroen; SOUZA, Cláudia de. Inclusão, colaboração e governança urbana: perspectivas brasileiras. In: CASTRO, Erika de; WOJCIECHOWSKI, Maciel John (Org.). Inclusão, colaboração e governança urbana Colaborativa. Rio de Janeiro: Observatório das Metrópoles; Belo Horizonte: Ed PUC Minas, 2010.

IBGE - INSTITUTO BRASILEIRO DE GEOGRAFIA E ESTATÍSTICA. Censo Demográfico 2010. Disponível em: <http://censo2010.ibge.gov.br〉. Acesso em: 28 jul. 2013.

KLINK, Jeroen Johannes. Governança das metrópoles: conceitos, experiências, perspectivas. São Paulo: Annablumme, 2010. 